\title{
Dynamic Network Planning of Underground Logistics System on Uncertainty Graph
}

\author{
YiHua Zhong $\mathbb{D}^{1},{ }^{1}$ ShiMing Luo, ${ }^{1,2}$ Min Bao, ${ }^{1}$ and XiaoDie $\mathrm{Lv}^{1,3}$ \\ ${ }^{1}$ School of Science, Southwest Petroleum University, Chengdu, Sichuan 610500, China \\ ${ }^{2}$ Neijiang Sixth Middle School, Neijiang, Sichuan 641100, China \\ ${ }^{3}$ School of Mathematics and Information Science, Neijiang Normal University, Neijiang, Sichuan 641100, China \\ Correspondence should be addressed to YiHua Zhong; zhongyh_65@126.com
}

Received 15 April 2019; Revised 30 July 2019; Accepted 8 August 2019; Published 23 October 2019

Guest Editor: C. De la O Francisco

Copyright (c) 2019 YiHua Zhong et al. This is an open access article distributed under the Creative Commons Attribution License, which permits unrestricted use, distribution, and reproduction in any medium, provided the original work is properly cited.

\begin{abstract}
When designing the underground logistics system, it is necessary to consider the uncertainty of logistics nodes, high cost, and high risk. This paper employed the theories of uncertain graph and dynamic programming to solve the network planning problem of underground logistics system. Firstly, we proposed the concepts of uncertainty measure matrix and vertices structure uncertainty graph by using uncertainty measure and uncertainty graph. Secondly, vertices structure uncertainty graph of the underground logistics system was constructed based on our proposed vertices structure uncertainty graph and the uncertainty of logistics nodes. Thirdly, the dynamic programming model of the underground logistics system was established, and its solution algorithm was also designed by improving simulated annealing. Finally, the correctness and feasibility of the method was validated by using a numerical example of the underground logistics system in Xianlin district, Nanjing City in China.
\end{abstract}

\section{Introduction}

Problems in transportation and logistics had been tackled well since computers and operational research (OR) became available [1]. However, a new challenge to transportation and logistics is the huge pollution and economic impact of transportation on the environment and logistic costs of companies. The underground logistics system (ULS) is the system of underground freight transportation and supply in inner city and among cities. It can reduce urban pollution by using electric energy to achieve transportation of low-carbon environmental protection. Moreover, it can also effectively reduce the cost and traffic pressure on the ground road to alleviate urban traffic congestion. At present, many countries in the world considered developing urban underground logistics system as a new way of alleviating traffic dilemma. Modern underground logistics system has been studied for nearly 30 years. The United States, Britain, Holland, and Japan just only carried out some of the engineering practices for the underground logistics system $[2,3]$, but there is still not any successful case as an example of studying [4]. Therefore, the international research for ULS is a relatively new expanding field.

The applications of the early ULS are various. American scholars proposed the freight transports by using underground pipeline or tube transport, which were driven by electricity to transport municipal refuse and coal. The Japanese scholars set up an underground mail system between the Tokyo station and the central post office. Holland scholars used the ULS to connect the Aalsmeer flower market, the Schiphol airport, and the Hoofddorp railway transfer station. By using the ULS, timeliness goods such as flowers may be transported in time [5]. But, nowadays the ULS is obviously different from the early transportation system in influence factors of their construction: the city scale and traffic network congestion [6]. The current studies on the ULS mainly focus on three aspects: feasibility analysis, risk assessment, and network planning of logistics system.

Based on the OLS-ASH project (which is used to illustrate the designing of such a highly automated freight transportation system), Pielage proposed and analyzed the 
underground freight transport system and its feasibility as well as its specific design steps with the transportation system in Holland [3]. Hane et al. took Tokyo as an example to analyze the influence degree of the cost-benefit of constructing ULS on the original logistics system [7]. In 2004, Qian first presented a new ULS system and studied the traffic congestion of Beijing in China [8]. Chen et al. used macroenvironment to analyze the applicability of the ULS in China's traffic environment and determined the internal and external factors affecting the system. Moreover, the relevant recommendations about risk assessment of building ULS were proposed based on the situation analysis framework [9]. van der Heijden et al. simulated and analyzed the operating characteristics of the underground logistics network structure and the constructing cost and efficiency among different regions [10].

The researches on the node layout and network optimization of the ULS are the hottest research. Johan analyzed and compared the characteristics of different network structures of the ULS, such as punctiform network, linear network, and reticular network [11]. Based on a definite graph whose vertices and edges are predetermined, Zhu et al. established the node location model of 0-1 linear programming to find the best logistics node [12]. Considering the characteristics of urban environment and logistics nodes, Erkayman et al. proposed the fuzzy TOPSIS (technique for order preference by similarity to an ideal solution) method of planning the logistics center [13]. From the point of view of transportation, construction, economy, technology, and sustainable development, Turskis and Zavadskas presented the ARAS-F (fuzzy additive ratio assessment) method to select the logistics center [14]. According to the stage characteristics of integration process on logistics facilities in Beijing, Tianjin, and Hebei, Guo and Zhuang proposed the cloud model to evaluate complex systems [15]. Yan and Qin adopted the bilevel programming model to select the location of the underground logistics nodes, including the upper-level planning model from the perspective of decision-makers and the lower-level planning model from the perspective of customers [16]. Based on plant growth simulation algorithm, Li optimized the network route of ULS in large cities [17]. Binsbergen and Johan studied the optimization method of the route layout in urban underground logistics network [18]. By applying multimodule network analytic hierarchy process (AHP) based on point, linear, and surface, $\mathrm{Mu}$ set up a model of set covering to study and analyze the problem of road planning of the ULS [19].

An important premise of the above studies on the ULS is that logistics nodes are predetermined. However, whether a logistics node of an ULS exists or not in real life depends on a number of factors such as total freight volume, transportation cost, traffic congestion index, construction cost, and traffic interruption. Because data and information of expert estimating and judging above those factors have not only fuzziness but also randomness or imprecision in studying the ULS, the above studies only solved the planning of the ULS with determinate logistics nodes. Obviously, it is not very appropriate to formulate the existence of logistics nodes and the edges connecting logistics nodes only by fuzzy theory or random theory. Uncertainty theory proposed in 2007 and refined in 2010 by Liu $[20,21]$ is a new tool to handle expert data with fuzziness or randomness or imprecision. In 2013, Gao and Gao first introduced uncertainty theory into graph models and proposed a concept of uncertain graph, in which the existence possibility (reliability) of each edge is described by uncertain measures [22]. It is well known that the ULS has the characteristic of high cost and high risk as well as difficulty improving. Moreover, the impact of logistics nodes on the whole system is different. From the view of ULS top-level design, the following problems should be focused: the time order and the evolution process about route construction of its optimal network. Therefore, a technical process for dynamic network planning of the ULS with vertices structure uncertainty graph may be obtained by applying dynamic network programming $[23,24]$ and extending uncertainty graph proposed by Gao and Gao [22, 23, 25].

In this paper, firstly, the uncertainty graph of logistics nodes will be constructed according to the definition of vertices structure uncertainty graph and the key degree of each logistics node proposed by us. Secondly, the time order of evolution process and dynamic programming model of ULS will be established based on the uncertainty graph of logistics nodes formulated by us. This uncertainty graph of logistics nodes includes the measure size of each logistics node, the measure size of each tunnel, and each network route. Thirdly, the simulated annealing algorithm will be designed to solve this dynamic network optimization model to obtain the evolution process of an ULS construction project. Finally, the optimal construction time order and dynamic evolution process of an ULS will be programmed with an ULS construction project in Xianlin district, Nanjing city, China, by using the method and algorithm proposed in the paper.

The remainder of this paper is organized as follows: in Section 2, uncertainty measures and uncertainty graphs are introduced and formulated. It includes uncertainty measures and the relative definitions of vertices structure uncertainty graph. In Section 3 the vertices structure uncertainty graph based on an uncertainty of logistics nodes is constructed. Section 4 establishes a dynamic programming model of ULS network construction. In Section 5, an algorithm to solve dynamic programming of the ULS based on the simulated annealing algorithm is designed. In Section 6, a numerical case is studied to demonstrate the correctness of concepts and methods proposed in this paper. Section 7 concludes this paper with a brief summary.

\section{Uncertainty Measure and Uncertainty Graph}

2.1. Uncertainty Measure. Let $\Gamma$ be a nonempty set and $\mathscr{L}$ be a $\sigma$-algebra over $\Gamma$. Each element $\Lambda$ in $\mathscr{L}$ is called an event. The set function $M$ is called an uncertain measure if it satisfies the following three axioms $[20,21]$.

Axiom 1 normality. $M\{\Gamma\}=1$.

Axiom 2 self-duality. $M\{\Lambda\}+M\left\{\Lambda^{c}\right\}=1$ for any event $\Lambda$.

Axiom 3 subadditivity. For every countable sequence of events $\left\{\Lambda_{i}\right\}_{i=1}^{+\infty}$, we have 


$$
M\left\{\cup_{i=1}^{\infty} \Lambda_{i}\right\} \leq \sum_{i=1}^{\infty} M\left\{\Lambda_{i}\right\} .
$$

The triplet $(\Gamma, L, M)$ is called an uncertainty space. Uncertainty measure is interpreted as the personal belief degree (not frequency) of an uncertain event that may happen. Thus, uncertainty measure and belief degree are synonymous. Uncertainty measure depends on the personal knowledge concerning the event. It will change if the state of knowledge changes. In other words, it may be understood simply as a probability $\mathrm{Pr}$ in a random environment, or a credibility measure $\mathrm{Cr}$ in the fuzzy environment, or a trust value $\operatorname{Tr}$ in the rough environment.

2.2. Vertices Structure Uncertainty Graph. The definition of an uncertain graph was first proposed by Gao and Gao [22] in 2013. But their definition assumed that the vertices in the graph are predetermined. Therefore, their definition may be considered as only applying to a special uncertain graph whose edges are not predetermined and whose existence possibility (reliability) of each edge is described by uncertain measures. It is called as the edge structure uncertainty graph by us. By analogy of its definition and the idea of adjacent matrix representing graph, we present definitions of uncertainty measure matrix and vertices structure uncertainty graph as follows.

Definition 1. The graph with uncertain vertices structure uniquely corresponds to an uncertainty measure matrix $\Phi=$ $\left(\phi_{i j}\right)_{n \times n}$ if and only if $\phi_{i j}$ satisfies the following:

(1) When $i=j, \quad \phi_{i i}=M\left\{v_{i}=1\right\}$ represents the uncertainty measure of vertex $v_{i}$ existence, which is simply denoted as $\phi_{i}$

(2) When $i \neq j, \phi_{i j}=M\left\{v_{i} v_{j}=1\right\}$ represents the uncertainty measure of the edge connecting vertex $v_{i}$ and vertex $v_{j}$

where $v_{i}=1$ indicates that vertex $\mathrm{i}$ exists, $v_{i}=0$ indicates that vertex $\mathrm{i}$ does not exist, $v_{i} v_{j}=1$ indicates that the edge connecting vertices $i$ and $j$ exists, and $v_{i} v_{j}=0$ indicates that the edge connecting vertices $i$ and $j$ does not exist.

Based on the uncertainty measure matrix and the definition of the edge structure uncertainty graph, we propose a definition of the vertices structure uncertainty graph as follows.

Definition 2. The graph with uncertain vertices structure is a three triple which can be denoted as $\mathcal{N}=(V, E, \Phi) . V$ is the vertex set, and $E$ is the edge set. $\Phi$ is the uncertainty measure matrix corresponding to an uncertain graph. It is simply called as a vertices structure uncertainty graph, where $V$ and $E$ determine the structure of the uncertain graph, and the uncertainty measure matrix $\Phi$ shows measures of vertices existing and measures of edges existing to connect these uncertain vertices in the graph.
For more intuitively understanding the edge structure uncertainty graph and the vertices structure uncertainty graph, Figure 1 gives a simple uncertain graph for vertices $A$, $\mathrm{B}$, and $\mathrm{C}$ and edges $\mathrm{AB}, \mathrm{AC}$, and $\mathrm{BC}$.

In Figure 1(a), if vertex $\mathrm{O}$ exists in an uncertainty measure $M$, then edges $\mathrm{OA}, \mathrm{OB}$, and $\mathrm{OC}$ must exist with uncertainty measures. Assuming that the edges $\mathrm{OA}, \mathrm{OB}$, and OC exist with the uncertainty measures $M_{a}, M_{b}$, and $M_{c}$, respectively, and $0 \leq M_{a}, M_{b}, M_{c}, M \leq 1$, then the uncertainty measure matrix corresponding to this graph satisfies the following:

$$
\Phi=\left(\begin{array}{cccc}
1 & 1 & 1 & M_{a} \\
1 & 1 & 1 & M_{b} \\
1 & 1 & 1 & M_{c} \\
M_{a} & M_{b} & M_{c} & M
\end{array}\right) .
$$

In Figure 1(b), if vertex $\mathrm{O}$ exists (that is, $M=1$ ), but edges $\mathrm{OA}, \mathrm{OB}$, and $\mathrm{OC}$ exist with uncertainty measures $M_{a}, M_{b}$, and $M_{c}$, respectively, then the uncertainty measure matrix corresponding to this graph satisfies the following:

$$
\Phi=\left(\begin{array}{cccc}
1 & 1 & 1 & M_{a} \\
1 & 1 & 1 & M_{b} \\
1 & 1 & 1 & M_{c} \\
M_{a} & M_{b} & M_{c} & 1
\end{array}\right)
$$

If vertex $\mathrm{O}$ does not exist (that is, $M=0$ ), then edges $\mathrm{OA}$, $\mathrm{OB}$, and $\mathrm{OC}$ must not exist, and then the uncertainty measure matrix corresponding to this graph satisfies the following:

$$
\Phi=\left(\begin{array}{llll}
1 & 1 & 1 & 0 \\
1 & 1 & 1 & 0 \\
1 & 1 & 1 & 0 \\
0 & 0 & 0 & 0
\end{array}\right) .
$$

Comparing the above three uncertainty measure matrices (2)-(4), we observe that matrices (3) and (4) are the special cases of matrix (2). Thus, the concept of vertices structure uncertainty graph proposed by us extends the concepts of the existing graphs, which may depict the concepts such as graph, probability graph, fuzzy graph, and uncertain graph.

\section{Vertices Structure Uncertainty Graph Based on the Uncertainty of Logistics Nodes}

3.1. Uncertainty Measure on the Existence of Logistics Nodes. When designing an ULS, the construction of logistics nodes on an area usually adopts location planning to make a preliminary determination [11-18]. The ULS has the characteristics of high cost and high risk as well as difficult improving. Especially, the impact of each logistics node on the whole logistics system is different. Thus, it is necessary to 


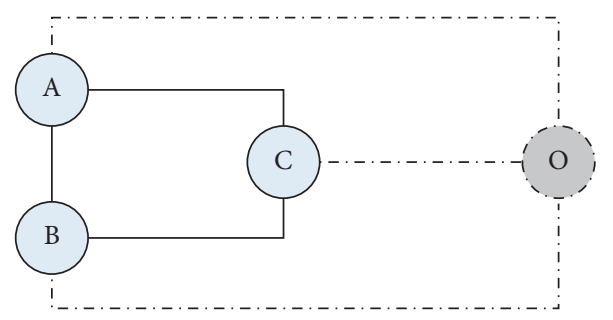

(a)

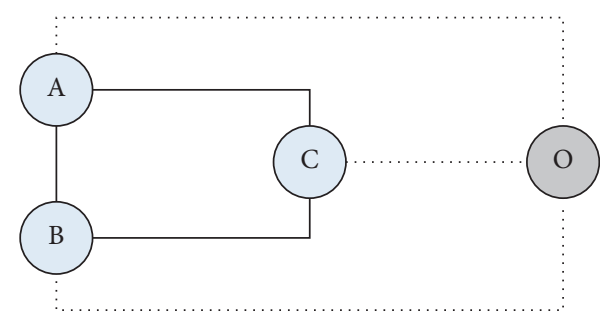

(b)

FIgUre 1: Two uncertain graphs with uncertain structure. (a) The vertex $\mathrm{O}$ exists in a measure. (b) The vertex $\mathrm{O}$ must exist and $\mathrm{OA}$, $\mathrm{OB}$, and OC must exist with a measure.

analyze and compute the key degree of each logistics node in the dynamic programming of an ULS network.

Let there be $n$ alternative logistics nodes in an ULS. Based on the impact degree of no-constructing logistics node $i$ on the whole logistics network, we present using the impact degree to depict the key degree of logistics node $i$. Let $U_{0}$ be the cost index of all logistics nodes operating normally (no interruption) and $U_{i}$ be the cost index of the $i$ th logistics node interrupting. The cost here could be the total freight volume, transportation cost, traffic congestion index, or construction cost of the ULS network. Thus, the key degree $M_{i}$ of the $i$ th logistics node may be computed by using the following formula:

$$
M_{i}=\frac{\left|U_{i}-U_{0}\right|}{U_{0}}
$$

where $M_{i}=0\left(U_{i}=U_{0}, i \in\{1,2, \ldots, n\}\right)$ means that the interruption of the $i$ th logistics node has no effect on the whole network; that is, the $i$ th logistics node is not important in the whole network. The bigger the $M_{i}$ is, the more critical the $i$ th logistics node is.

From the point of view of graph theory, the key degree of each logistics node decides the possibility of the corresponding vertex (logistics node) existence in the ULS. That is, the uncertainty measure of vertex existence is different.

The bigger the key degree is, the bigger the possibility of the vertex existence is, and vice versa. By standardization key degree $M_{i}$, the $i$ th vertex uncertainty measure can be obtained according to the following formula:

$$
\phi_{i}=\frac{M_{i}-\min _{i \in\{1,2, \ldots, n\}}\left\{M_{i}\right\}}{\max _{i \in\{1,2, \ldots, n\}}\left\{M_{i}\right\}-\min _{i \in\{1,2, \ldots, n\}}\left\{M_{i}\right\}} \times 100 \% .
$$

\subsection{Uncertainty Measure of the Edge Connecting Two Logistics} Nodes. In an ULS network, if a logistics node does not exist, then the edges connecting it must not exist. According to this phenomenon, the uncertainty of an edge (route) may be depicted by using the freight volume.

If $h_{i j}$ represents the freight volume of from logistics node $i$ to logistics node $j$, then the uncertainty measure of the edge connecting vertices $i$ and $j$ may defined as follows:

$$
\phi_{i j}=\frac{h_{i j}-\min _{i, j \in\{1,2, \cdots n\}}\left\{h_{i j}\right\}}{\max _{i, j \in\{1,2, \ldots, n\}}\left\{h_{i j}\right\}-\min _{i, j \in\{1,2, \ldots, n\}}\left\{h_{i j}\right\}} \times 100 \%
$$

3.3. Vertices Structure Uncertainty Graph. According to definition 2 and Sections 3.1 and 3.2, an ULS network may model as an uncertainty graph $\mathcal{N}=(V, E, \Phi)$. In which, logistics node $i$ is taken as vertex $v_{i}(i \in\{1,2, \ldots, n\})$ of the graph, where $n$ is the total number of logistics nodes, and the vertex set is denoted as $V=\left\{v_{1}, v_{2}, \ldots, v_{n}\right\}$; the transportation road (or tunnel) between vertex $v_{i}$ and vertex $v_{j}$ is taken as an edge $e_{k}(k \in\{1,2, \ldots, m\})$ of the graph, where $m$ is the total number of edges of the graph, and the edge set of the graph is denoted as $E=\left\{e_{1}, e_{2}, \ldots, e_{m}\right\} ; \quad$ uncertainty measure matrix $\Phi=\left(\phi_{i j}\right)_{n \times n}$, when $i=j, \phi_{i i}=\phi_{i}$, and it may be computed by using formula (6); when $i \neq j, \phi_{i j}$ may be computed by using formula (7). Thus, a schematic diagram on logistics nodes of vertices structure uncertainty graph is shown in Figure 2.

In Figure 2, numbers on vertices and edges represent uncertainty measures for logistics nodes and transportation roads (or tunnels) in the ULS, which can be calculated by using formulas (6) and (7), respectively. The number 1.0 at vertices $B, E$, and $D$ means that the effects of logistics nodes $\mathrm{B}, \mathrm{E}$, and $\mathrm{D}$ on the cost index of ULS are the same. Moreover, their effects are the greatest among the effects of logistics nodes on the cost index of the ULS. Therefore, logistics nodes $\mathrm{B}, \mathrm{E}$, and $\mathrm{D}$ must exist in the vertices structure uncertainty graph of the ULS. The numbers 0.5 and 0.7 at nodes $\mathrm{A}$ and $\mathrm{C}$ mean that they are less important than nodes $\mathrm{B}, \mathrm{E}$, and $\mathrm{D}$, and the possibilities of their existing in the vertices structure uncertainty graph of ULS are 0.5 and 0.7 , respectively. The numbers $0.7,0.2$, and 0.3 on edges $\mathrm{BA}, \mathrm{AC}$, and $\mathrm{BC}$ mean that the possibilities of building transport roads (or tunnels) $\mathrm{BA}, \mathrm{AC}$, and $\mathrm{BC}$ between nodes $\mathrm{B}, \mathrm{A}$, and $C$ are $0.7,0.2$, and 0.3 , respectively; the number 1.0 on edges $\mathrm{BE}$ and $\mathrm{DB}$ means that transport roads (or tunnels) $\mathrm{BE}$ and DB must be built between nodes $\mathrm{B}, \mathrm{D}$, and $\mathrm{E}$, while the number 0.4 on edge $\mathrm{DE}$ means that the possibility of building transport road (or tunnel) DE between nodes $\mathrm{D}$ and $\mathrm{E}$ is only 0.4 . 


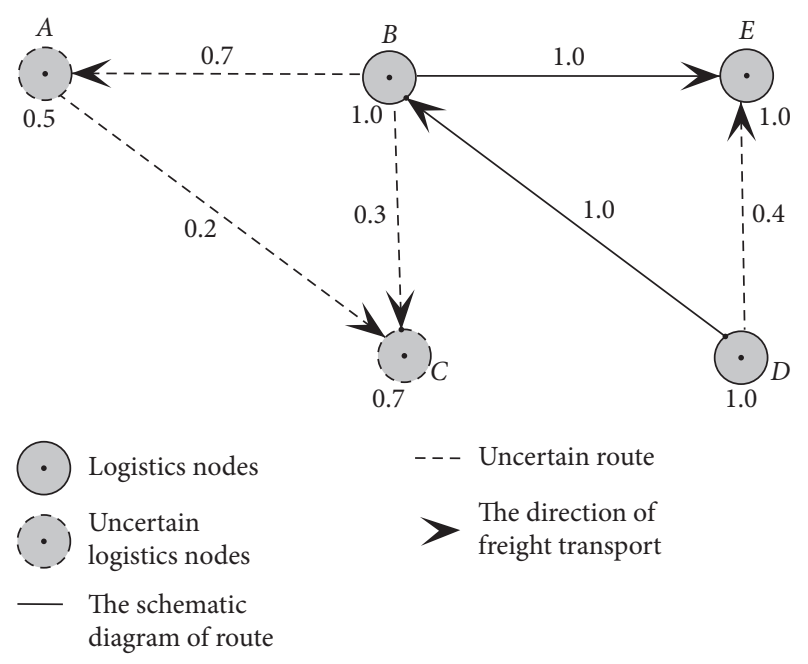

Figure 2: Schematic diagram on logistics nodes of vertices structure uncertainty graph.

\section{Dynamic Programming Model of ULS Network Construction}

In view of the above analysis in Section 3, we may establish a dynamic programming model of the ULS network construction to obtain its schedule and dynamic evolution process. Let an ULS have $n$ logistics nodes and $m$ tunnels. Then, it may model as an uncertainty graph with $n$ vertices and $m$ edges based on the vertices structure uncertainty graph. During the process of construction, it usually needs to be completed in $r$ years. If the total route length of the ULS is $D_{\text {total }}$, then the tunnel (route) length to be built in every year is $D_{\text {wish }}=D_{\text {total }} / r$. Therefore, construction process in a year may be analyzed as follows:

(1) Number the logistic nodes according to the decreasing order of their uncertainty measures $\phi_{i}, i=1,2, \ldots, n$

(2) Schedule the ULS network routes to be constructed in the order of $1,2, \ldots, m$ based on the vertices structure uncertainty graph; that is, the ULS network has $m$ edges

(3) Establish dynamic programming model

4.1. Set Variables. Let a route be built at each stage. Then, we may set the following variables:

$k$ : stage variable $k \in\{1,2, \ldots, m\}$.

$d_{k}$ : the length of the $k$ th route, as the distance of edge $\mathrm{BC}$ is $5 \mathrm{~km}$ in Figure 3 .

$c_{k}$ : the value of the $k$ th route connecting vertices $v_{i}$ and $v_{j}$; that is, the uncertain measure $\phi_{i j}$ of edge $e_{k}$ existing, as an example $c_{k}=0.3$ means the uncertain measure of edge BC existing in Figure 3.

$S_{k+1}$ : the total length of previous $k$ routes (tunnels) allowed to be constructed in the ULS network at the beginning of the $k$ th stage, where $S_{1}=0$.

$x_{k}$ : whether the $k$ th route is built or not, where $x_{k}=0$ means that it is not built and $x_{k}=1$ means that it is built.

4.2. State Transfer Functions. Because the total length of previous $k-1$ routes (tunnels) allowed to be constructed before the $k$ th stage is $S_{k}$, the length of the tunnel constructed in the $k$ th stage is $d_{k} \cdot x_{k}$, and the total length of previous $k$ routes (tunnels) allowed to be constructed in the ULS network at the beginning of the $k$ th stage $S_{k+1}=S_{k}+d_{k} \cdot x_{k}$. Then, the state transfer equation of the total length of the tunnel allowed to be constructed is as follows:

$$
S_{k}=S_{k+1}-d_{k} \cdot x_{k}, \quad k=1,2, \ldots, m .
$$

A graphic description that graphically explains what different variables represent can be seen in Figure 3. Figure 3(a) shows that the total length of a tunnel allowed to be constructed before the beginning of stage 1 is $S_{1}=0$. The length of tunnel BD constructed in the first stage is 7 , so the total length of previous 1 tunnel allowed to be constructed at the beginning of the first stage is $S_{2}=S_{1}+d_{1} \cdot x_{1}=0+7 \times 1=7$. Figure $3(\mathrm{~b})$ shows that the length of a tunnel allowed to be constructed before the beginning of stage 2 is $S_{2}=7$. The length of tunnel BE constructed in the second stage is 6 , so the total length of previous 2 tunnels allowed to be constructed at the beginning of the second stage is $S_{3}=S_{2}+d_{2} \cdot x_{2}=$ $7+6 \times 1=13$.

4.3. Fundamental Equation. Assuming that $f_{k}\left(S_{k+1}\right)$ represents the maximum value that the total length of being allowed construction routes is less than $S_{k+1}$, only previous $k$ routes are built by optimal strategy. Then, the sequential recursion relation is as follows:

$$
\left\{\begin{array}{l}
f_{k}\left(S_{k+1}\right)=\max _{0 \leq d_{k} x_{k} \leq S_{k+1}}\left\{c_{k} x_{k}+f_{k-1}\left(S_{k+1}-d_{k} x_{k}\right)\right\}, \\
k=1,2, \ldots, m, \\
f_{0}\left(S_{1}\right)=0 .
\end{array}\right.
$$

For more easy calculation, equation (9) is transformed into the following recursion relation formula:

$$
\begin{cases}f_{k}\left(S_{k+1}\right)=\max _{0 \leq x_{k} \leq\left[S_{k+1} / d_{e_{k}}\right]}\left\{c_{k} x_{k}+f_{k-1}\left(S_{k+1}-d_{k} x_{k}\right)\right\}, & k=1,2, \ldots, m, \\ f_{0}\left(S_{1}\right)=0 . & \end{cases}
$$

Through calculating by the recursion relation equation (10) in sequence, the optimal result of construction routes can be obtained. 


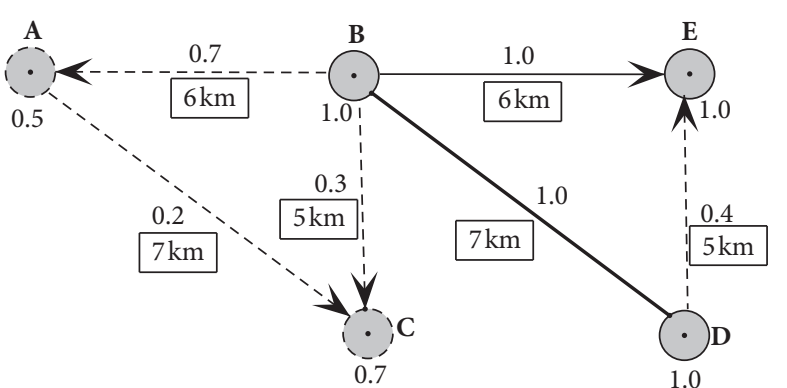

(a)

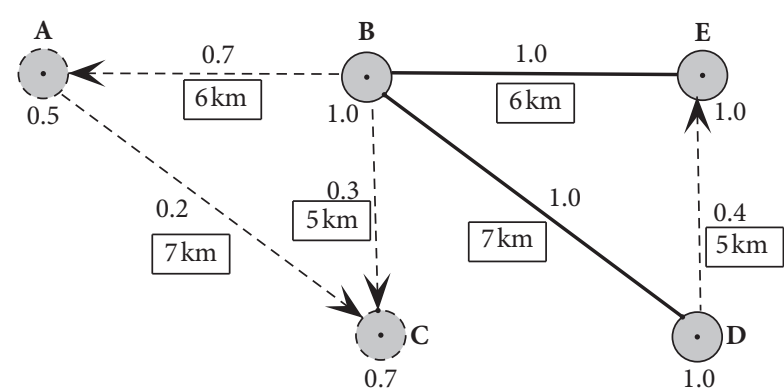

(b)

FIGURE 3: A graphic description that graphically explains what different variables represent.

\section{A Dynamic Programming Algorithm for ULS Construction Based on Simulated Annealing Algorithm}

The idea of original simulated annealing (SA) algorithm comes from the physical annealing process $[19,26]$. It is often used to solve the problem of combinatorial optimization. Obviously, the problem of ULS construction planning is a combinatorial optimization problem with uncertain measures based on Section 4. Therefore, we present an improving SA to solve the problem of ULS construction project.

5.1. The Idea of Improving SA Algorithm. The idea is first to compute the uncertainty measures on logistics nodes and transportation roads (tunnels) connecting logistics nodes to establish the network road of ULS with the vertices structure uncertainty graph and then to use solid annealing to simulate the combinatorial optimization problem [27, 28], which is as follows.

Firstly, according to the cost index of each logistics node and the existing freight volume in logistics system, the uncertainty measures of logistics nodes and transportation roads (tunnels) between logistics nodes are computed. Based on these, the network road of the ULS with the vertices structure uncertainty graph is established.

Then, in order to get the transportation road (tunnel) construction process, priority should be given to the establishment of key logistics nodes and key tunnels associated with key logistics nodes on the basis of the different degrees of impact of each node on the whole logistics system and the different demands of freight volume on each transportation road (tunnel).

Secondly, when the critical degree of logistics nodes is the same, priority should be given to the construction of transportation roads (tunnels) with larger freight volume.

Comparing it with the original simulated annealing algorithm, the differences lie in the process of judging the generation and acceptance of new solutions. Firstly, the uncertainty measures of vertices and edges are calculated, and the edges associated with the vertices having larger uncertainty measures are selected as candidate sets. Then, the uncertainty measures on the edges of candidate sets are judged. Secondly, in simulating internal energy $E$, the computation of $E$ being taken as objective function value $f$, the value (freight volume) of the tunnels needs to be first calculated as the uncertain measures $\phi_{i j}$ of the network roads of the ULS.

5.2. The Steps of Improving SA Algorithm. On the basis of the above idea and the algorithm of original SA, the concrete steps of the improving SA algorithm are as follows:

Step 1: compute the uncertainty measures on logistics nodes and transportation roads (tunnels) connecting logistics nodes of the ULS with the vertices structure uncertainty graph.

Step 2: number the logistic nodes according to the decreasing order of their uncertainty measures $\phi_{i}, i=1,2, \ldots, n$.

Step 3: schedule the ULS network routes to be constructed in the order of $k=1,2, \ldots, m$ based on the decreasing order of their uncertainty measures $\phi_{i j}$ of the existing edge $e_{k}$.

Step 4: determine the solution space $S=\left\{x_{1}, x_{2}, \ldots, x_{m} \mid \sum_{k=1}^{m} d_{k} x_{k}<D_{\text {wish }}\right\}$, where each feasible solution is represented by using a binary string.

Step 5: determine the internal energy $E$. The internal energy $E$ is depicted as the objective function value $f$-the value (freight volume) of the tunnels; i.e., $E=f\left(x_{1}, x_{2}, \ldots, x_{m}\right)=\sum_{k=1}^{m} c_{k} x_{k}, c_{k}=\phi_{i j}$.

Step 6: let the initial temperature $t$ and initial solution $x=x_{0}$.

Step 7: generate a new solution $x_{t}$. A route edge (tunnel) $x$ is first selected randomly. If it is not in the ULS that has been constructed, then it will allow to be constructed as a new solution $x=x_{t}$. Otherwise, the next tunnel of $x$ is chosen randomly as the edge $x_{t}$; that is, a new solution is generated by choosing $x_{t}$ in the neighborhood of $x$.

Step 8: internal circulation.

(1) Calculate objective function values $E$ corresponding to $x$ and $x_{t}$. If the objective function value of $x_{t}$ is less than that of $x$, then stop and let $x=x_{t}$. 


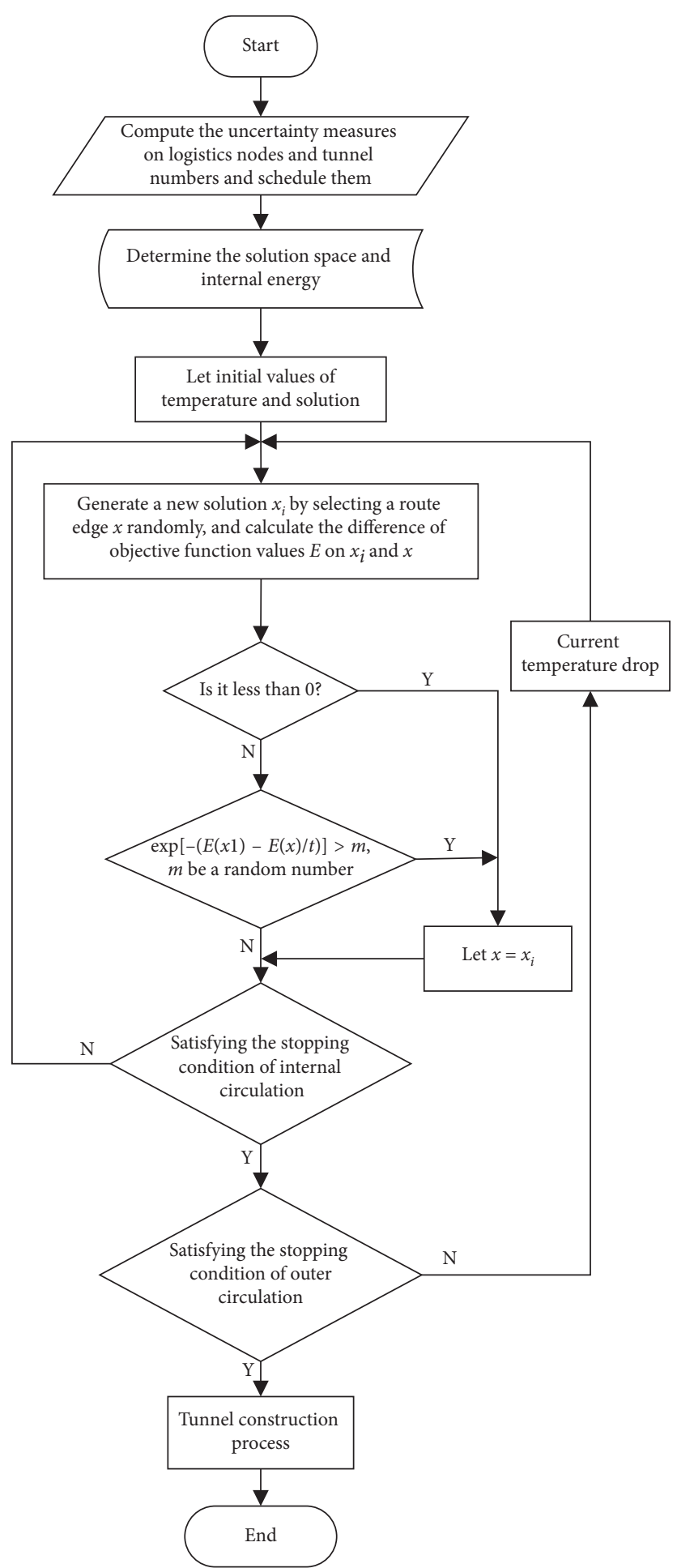

FIgURE 4: The flow diagram of the improving SA algorithm.

Otherwise, if $\exp \left[-\left(E\left(x_{t}\right)-E(x)\right) / t\right]>\mathcal{E}$, where $\varepsilon \in(0,1)$ is a random number, then stop and let $x=x_{t}$.

(2) When the stop condition in (1) is not satisfied, then update $t$ and repeat (1).

Step 9: external circulation.
(1) Cool down according to equations (11)-(13).

(2) If the stop condition of external circulation is not satisfied, then go to Step 5. Otherwise, stop the algorithm, where the value difference $\Delta f$ and the length difference $\Delta d$ in the edge of planning to be built tunnel in the ULS are satisfied, respectively: 


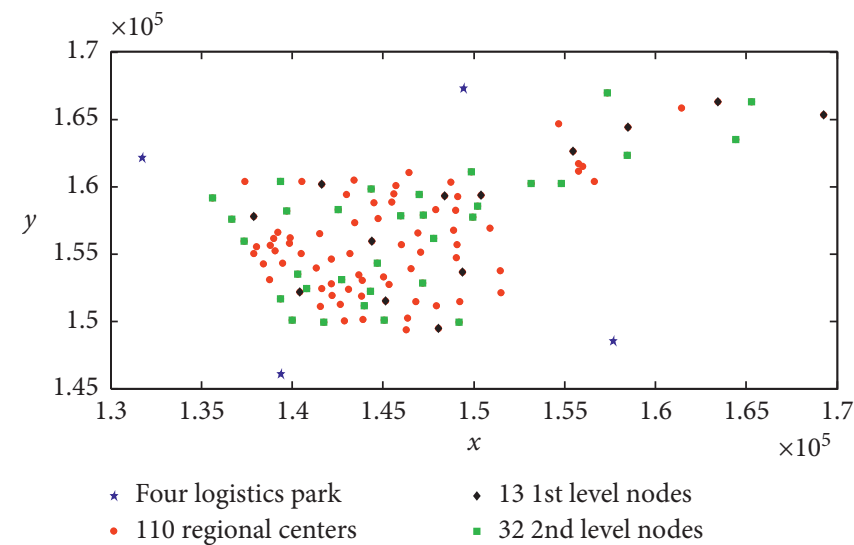

Figure 5: Position distribution of logistics nodes at all levels in Xianlin district.

TABLE 1: The related data of logistics nodes.

\begin{tabular}{|c|c|c|c|c|}
\hline Number & $X$ position & $Y$ position & Inflow & Outflow \\
\hline 1 & 148037.4 & 149443.9 & 1544.086 & 1528.184 \\
\hline 2 & 145146.8 & 151489.6 & 11698.71 & 11064.55 \\
\hline 3 & 140416.6 & 152146.1 & 14112.56 & 14103.54 \\
\hline 4 & 149366.9 & 153648.1 & 9541.856 & 9226.744 \\
\hline 5 & 144403.3 & 155930 & 10114.65 & 12104.62 \\
\hline 6 & 137889.7 & 157781.7 & 8299.6 & 8540.79 \\
\hline 7 & 141629.7 & 160163.7 & 6707.157 & 5996.62 \\
\hline 8 & 148375.7 & 159294.3 & 7146.025 & 6914.614 \\
\hline 9 & 150413.2 & 159364.7 & 10813.93 & 9715.012 \\
\hline 10 & 155477.4 & 162651.1 & 6601.267 & 5761.77 \\
\hline 11 & 158487.3 & 164413.4 & 6442.007 & 5625.619 \\
\hline 12 & 169251.1 & 165333.2 & 153.939 & 252.769 \\
\hline 13 & 163428 & 166293.4 & 6622.373 & 6225.333 \\
\hline 14 & 141732.2 & 149908 & 2826.742 & 2689.738 \\
\hline 15 & 145062.7 & 150092.6 & 2546.253 & 2431.514 \\
\hline 16 & 139998.8 & 150082.7 & 2334.953 & 2429.127 \\
\hline 17 & 149198.5 & 149918.9 & 2129.194 & 2057.143 \\
\hline 18 & 143976.3 & 151159.2 & 1634.509 & 1524.001 \\
\hline 19 & 144302.1 & 152239.5 & 964.361 & 865.667 \\
\hline 20 & 140808.2 & 152432.5 & 3241.555 & 3426.522 \\
\hline 21 & 139366.7 & 151652.6 & 2525.864 & 2662.456 \\
\hline 22 & 142733.4 & 153099.6 & 2782.18 & 2505.738 \\
\hline 23 & 147188.8 & 152823.2 & 4208.429 & 4041.365 \\
\hline 24 & 140309.2 & 153473.8 & 2993.329 & 2710.818 \\
\hline 25 & 144691 & 154317 & 2317.39 & 2754.09 \\
\hline 26 & 147771.4 & 156163 & 2351.513 & 2176.283 \\
\hline 27 & 149951.9 & 157738.3 & 4753.68 & 4090.284 \\
\hline 28 & 137348.1 & 155938.5 & 4021.458 & 3672.704 \\
\hline 29 & 136656.2 & 157553.6 & 1751.44 & 1809.175 \\
\hline 30 & 139713.8 & 158198.1 & 2784.112 & 2434.092 \\
\hline 31 & 142527.8 & 158313 & 3553.178 & 2896.085 \\
\hline 32 & 135607.1 & 159148.9 & 1088.694 & 1851.249 \\
\hline 33 & 144348.9 & 159828.8 & 987.691 & 966.32 \\
\hline 34 & 139356.9 & 160405.2 & 2285.787 & 2269.248 \\
\hline 35 & 145961.8 & 157814.7 & 1255.392 & 1330.97 \\
\hline 36 & 147221.1 & 157904.4 & 3301.446 & 2454.303 \\
\hline 37 & 150211.9 & 158547.6 & 4969.057 & 4677.888 \\
\hline 38 & 146987.7 & 159418.2 & 4904.498 & 4855.147 \\
\hline 39 & 149877.2 & 161091 & 859.515 & 884.769 \\
\hline 40 & 154830.1 & 160255.1 & 4260.346 & 3322.93 \\
\hline 41 & 153147 & 160216.5 & 2080.225 & 1882.86 \\
\hline 42 & 164429.9 & 163490 & 2661.528 & 1977.437 \\
\hline 43 & 158431.3 & 162322.4 & 2955.537 & 2692.746 \\
\hline 44 & 165296 & 166307.5 & 967.672 & 1021.723 \\
\hline 45 & 157354.7 & 166956.7 & 2378.161 & 1880.603 \\
\hline
\end{tabular}




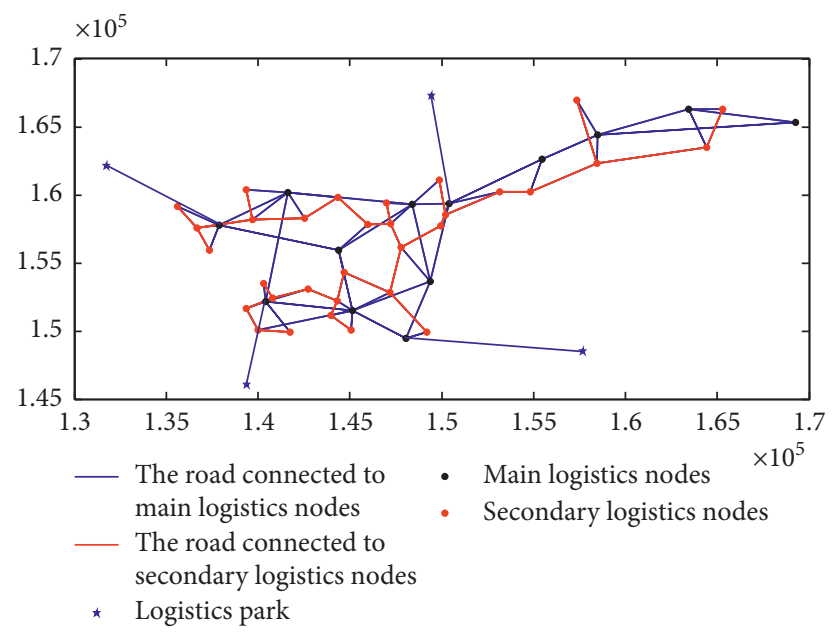

FIGURE 6: The network road of ULS.

$\Delta f= \begin{cases}c_{i}, & \text { constructing the } i \text { th tunnel during the period, } \\ c_{i}-c_{j}, & \text { constructing the } i \text { th tunnel and not constructing the } j \text { th tunnel in the period, } \\ c_{j}-c_{i}, & \text { constructing the } j \text { th tunnel and not constructing the } i \text { th tunnel during the period, }\end{cases}$

$\Delta d= \begin{cases}d_{i}, & \text { constructing the } i \text { th tunnel during the period, } \\ d_{i}-d_{j}, & \text { constructing the } i \text { th tunnel and not constructing the } j \text { th tunnel in the period, } \\ d_{j}-d_{i}, & \text { constructing the } j \text { th tunnel and not constructing the } i \text { th tunnel during the period, }\end{cases}$

$$
p= \begin{cases}0, & \text { if } d+\Delta d>D_{\text {wish }}, \\ 1, & \text { if } d+\Delta d \leq D_{\text {wish }}, \text { and } \Delta f>0 \\ \exp \left(\Delta f / t_{k}\right), & \text { otherwise }\end{cases}
$$

$\Delta d$ is the mileage increment of the total length of constructing the tunnels in the current planning. When planning to construct the tunnels, it is not known whether the tunnel will be built or not. Therefore, the extended metropolis criterion rule is used to compute $p$ : where $t_{k}$ is the temperature control parameter.

5.3. The Flow Diagram of Improving SA Algorithm. The flow diagram of the improving SA algorithms can be seen in Figure 4.

\section{Case Study}

6.1. Problem. The ULS dynamic network programming method proposed in this paper is used to plan the optimal schedule of network route construction in Xianlin district, Nanjing city, based on the underground logistics system (ULS) mentioned in question F of the 14th "Huawei cup" China Postgraduate Mathematic Contest in Modelling in 2017. The network construction project of underground logistics system requires constructing 45 logistics nodes (the numbers $1-13$ are the 1 st level nodes; the numbers $14-45$ are the 2nd level nodes) and 81 tunnels (the total length is $290 \mathrm{~km}$ ) during the 8 th year. Figure 5 shows position distribution of logistics nodes at all levels; Table 1 gives the related data of the nodes and tunnels on the ULS.

6.2. The Uncertainty Graph on Logistics Nodes. Using the method of formulating the vertices structure uncertainty graph based on the uncertainty of logistics nodes in Section 3 , the network road of the ULS with the vertices structure uncertainty graph is as shown in Figure 6.

6.3. The Construction Schedule and Dynamic Evolution Process of ULS Network Route. Based on the methods in Sections 4 and 5, let parameters of the improving SA algorithm be as follows: cutoff temperature $\mathrm{TF}=0.000001$, annealing factor $a=0.9$, initial temperature $T=100$, and iterations res $=8100$. By using the improving SA, we obtained the total number of tunnels to plan to be built and the corresponding serial numbers of tunnels, the actual total length network to plan to be completed, and the total freight volume in each year during 8 years, which can be seen in Table 2. Table 2 shows that the total length to be established in every year is roughly the same. The tunnel with bigger uncertainty measure of 
TABLE 2: The relevant data tables for the tunnel construction in each year.

\begin{tabular}{lcccc}
\hline & $\begin{array}{c}\text { Total flow of freight } \\
\text { transport }\end{array}$ & $\begin{array}{c}\text { Total length of } \\
\text { tunnels }\end{array}$ & $\begin{array}{c}\text { Total number of } \\
\text { tunnels }\end{array}$ & The number of constructed tunnels \\
\hline First year & 302.476 & 39.468 & 19 & $2,5,6,25,27,29,32,35,54,60,61,64,65,68,69$, \\
Second & 288.073 & 36.332 & 10 & $71,73,75,44$ \\
year & 110.929 & 36.550 & 10 & $7,13,17,22,23,38,40,47,50,81$ \\
Third year & 115.789 & 36.371 & 10 & $1,9,11,14,20,21,24,31,37,43$ \\
Fourth year & 121.275 & 36.829 & 9 & $3,4,12,15,26,30,33,36,41,45$ \\
Fifth year & 127.338 & 35.346 & 7 & $8,10,19,49,52,56,53,57,59$ \\
Sixth year & 133.705 & 36.967 & 9 & $16,28,42,46,77,79,80$ \\
Seventh & 144.786 & 32.137 & 7 & $18,34,39,48,51,62,63,66,67$ \\
year & 1344.371 & 290 & 81 & $55,58,70,72,74,76,78$ \\
Eighth year & & & \\
Total & & & & \\
\hline
\end{tabular}

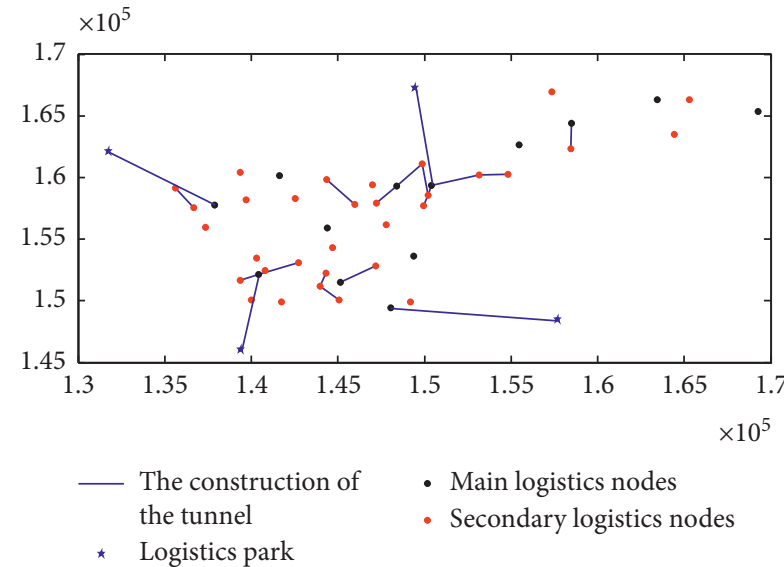

(a)

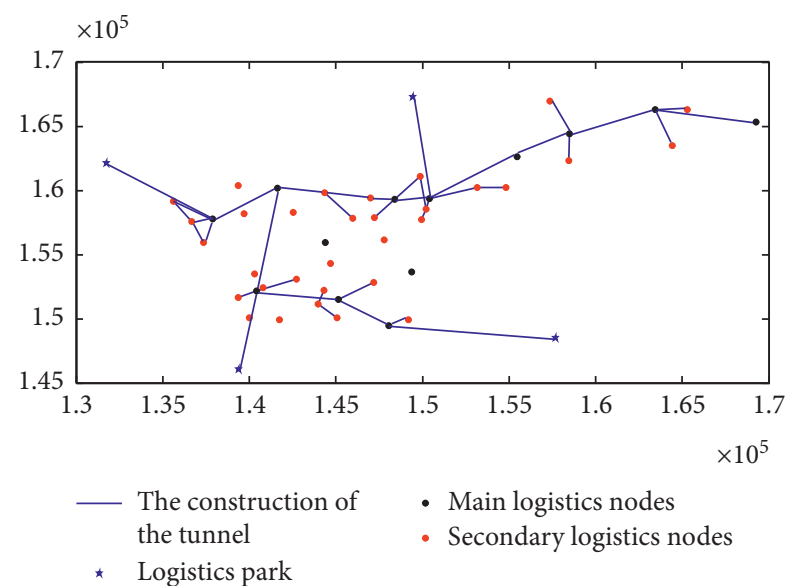

(c)

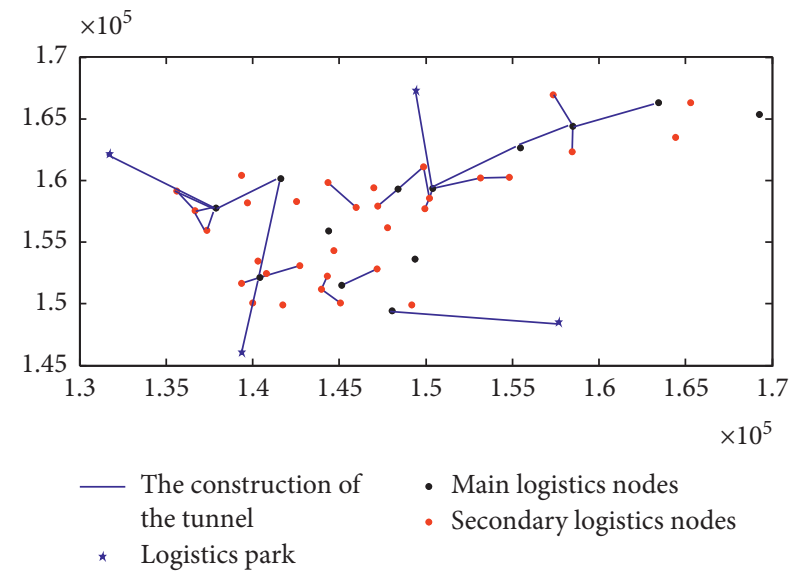

(b)

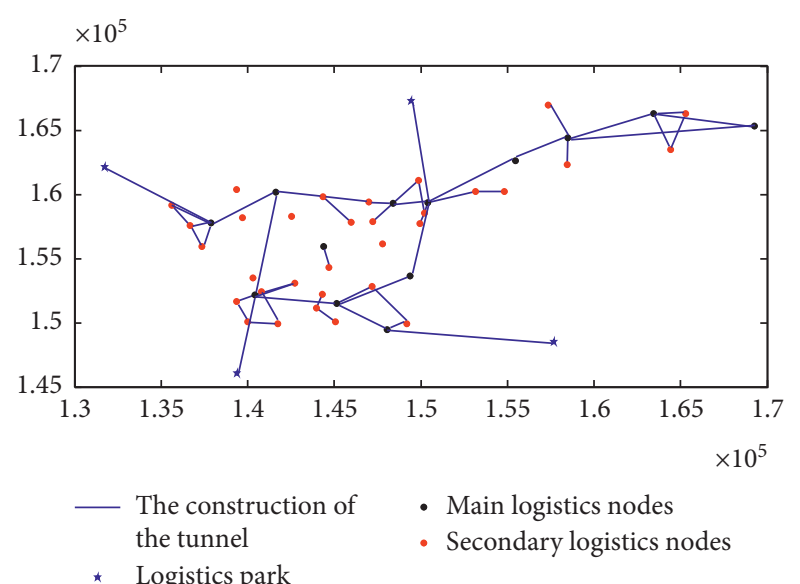

(d)

Figure 7: Continued. 


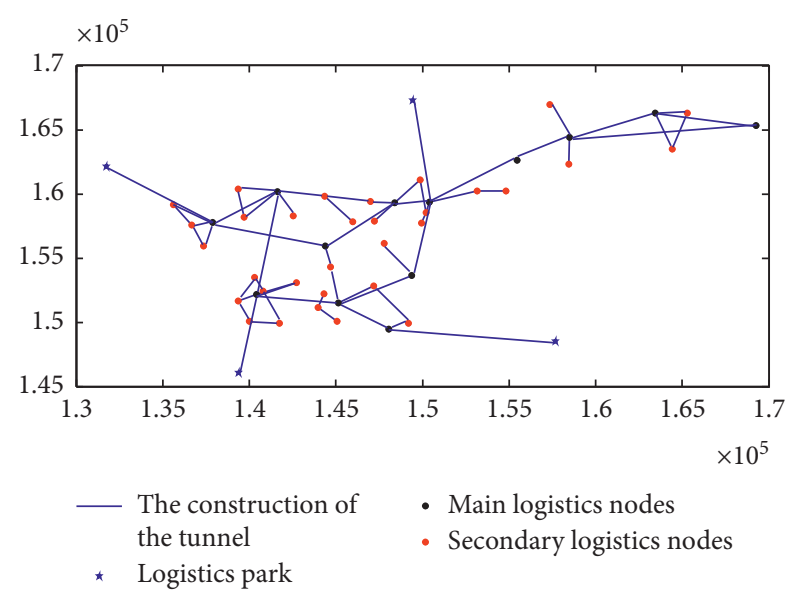

(e)

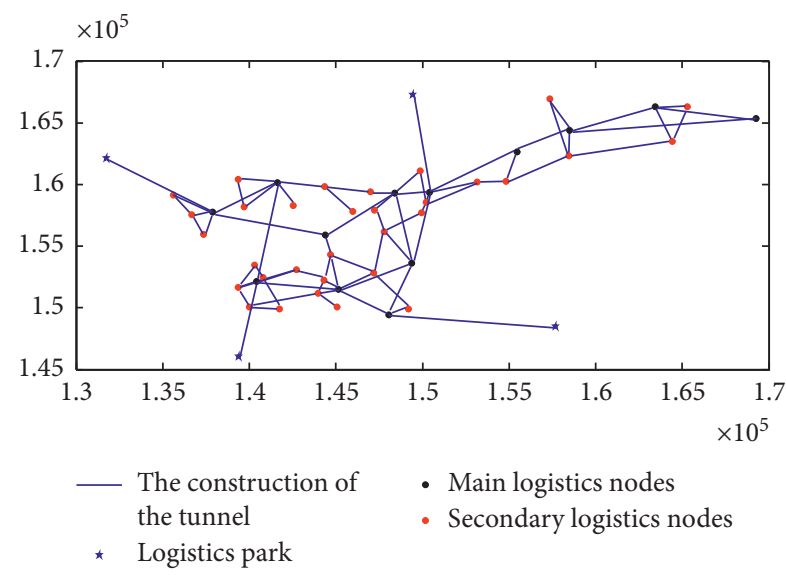

(g)

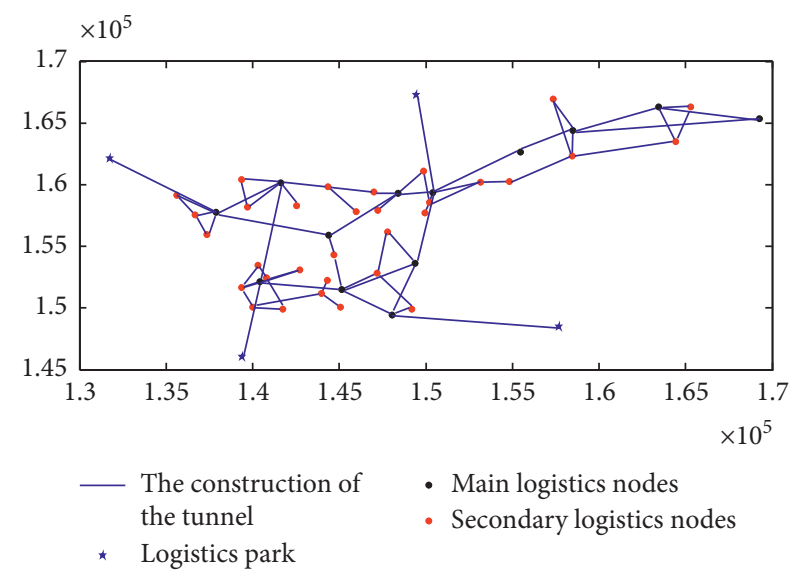

(f)

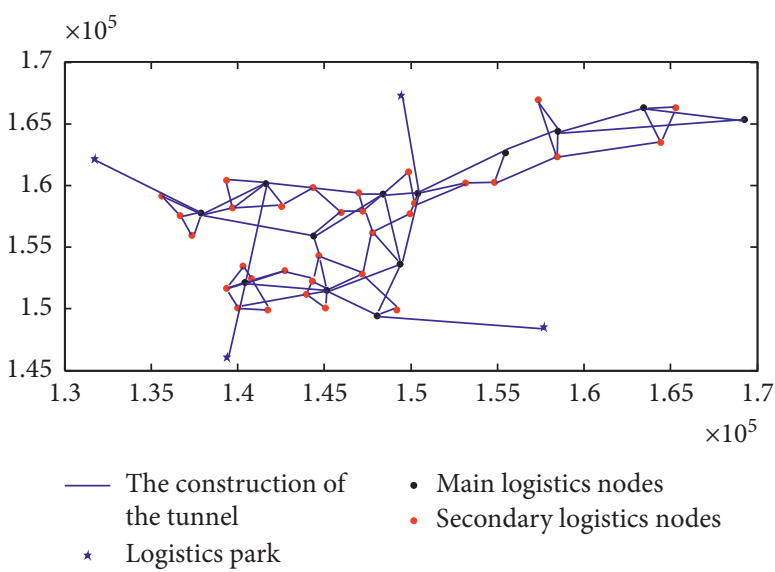

(h)

Figure 7: The evolution process of ULS construction. (a) First year. (b) Second year. (c) Third year. (d) Fourth year. (e) Fifth year. (f) Sixth year. (g) Seventh year. (h) Eighth year.

logistics nodes existing is always constructed in priority. That is, the relevant logistics nodes and tunnels with larger total freight volume are constructed in priority during the previous two years.

In addition, Figure 7 gives the evolution process of the whole underground logistics network construction in this district. That is, it gives a schedule chart of tunnel construction that is actually built each year in 8 years.

It can be seen from Figure 7 that the network built in every year is a block except the first year. It is because that the freight volume of each logistics node is also relatively large around the logistics node with large freight volume. Although the construction network in the first year seems to be scattered, it was found that most of the tunnels built in the first year are connected with the key logistics nodes. Because the key degree (the freight volume) is relatively large at the key logistics nodes, the key nodes should be given priority in the top layer design.

\section{Conclusion}

For the ULS being a new type of efficient transportation system, the route construction planning of the ULS network is essentially a key step of constructing ULS. Because the dynamic network planning of the ULS is a complex problem, we used comprehensively the graph theory, optimization theory, uncertain programming, dynamic optimization model, and simulated annealing algorithm to study it. After the relevant information of ground freight traffic is available, firstly, the influence degree of a logistics node interruption on the whole logistics network is used to depict the key degree of the logistics node, and it formulates the uncertainty measure of the logistics node. For the bigger the freight volume is, the bigger the possibility of the edge existence is; thus, the freight volume is used to express the uncertainty measure of edge connecting two logistics nodes. Secondly, a vertices structure uncertainty graph is formulated. Finally, a dynamic programming model of the ULS network construction is made, and an improving simulated annealing algorithm is designed to solve dynamic network optimization and the schedule problem of the ULS construction. The optimal time process of the network route construction in Xianlin district, Nanjing, China, shows that the ideas and methods proposed in this paper are correct and feasible. The established programming model and the design algorithm are effective and reliable for solving the network optimization of the ULS. 
About the route construction planning of the ULS network, we only study its dynamic network programming of the ULS with uncertain logistics nodes. It has still many problems worth studying, such as uncertain programming model of its route based on expected-value model, chance-constrained programming, and dependent-chance programming; network layout based on linear graph, ring graph, and grid graph; and its programming problem of considering more comprehensive uncertainty factor.

\section{Data Availability}

The data used to support the findings of this study are available from the corresponding author upon request.

\section{Conflicts of Interest}

The authors declare that they have no conflicts of interest.

\section{Acknowledgments}

This work was supported by the Double First-Rate Higher School Construction Foundation of Sichuan Finance Department and Education Department (Grant no. 2050205).

\section{References}

[1] M. G. Speranza, "Trends in transportation and logistics," European Journal of Operational Research, vol. 264, no. 3, pp. 830-836, 2018.

[2] O. N. Egbunike and A. T. Potter, "Are freight pipelines a pipe dream? A critical review of the UK and European perspective," Journal of Transport Geography, vol. 19, no. 4, pp. 499-508, 2011.

[3] B. J. Pielage, "Underground freight transportation. A new development for automated freight transportation systems in the Netherlands," in Proceedings of the IEEE Intelligent Transportation Systems, pp. 762-767, Oakland, CA, USA, August 2001.

[4] I. E. Zevgolis, A. A. Mavrikos, and D. C. Kaliampakos, "Construction, storage capacity and economics of an underground warehousing-logistics center in Athens, Greece," Tunnelling and Underground Space Technology, vol. 19, no. 2, pp. 165-173, 2004.

[5] N. Rezaie, A. Tabesh, M. Najafi, B. Ma, and S. H. Mousavipour, "Evaluation of applications and the comparison of routes for underground freight transportation in Texas," in Proceedings of the Pipelines 2016, pp. 847-856, Kansas City, MO, USA, July 2016.

[6] E. Kulińska and M. Odlanicka-Poczobutt, "Facilitation of urban transport through a pipeline supply network," Transportation Research Procedia, vol. 16, pp. 255-265, 2016.

[7] K. Hane, K. Okutsu, N. Matsui, and S. Kosugi, "Applicability of pneumatic capsule pipeline to radioactive waste disposal facility," New Pipeline Technologies, SecurityeSafety, vol. 36, pp. 1615-1624, 2003.

[8] Q. H. Qian, "Construction of underground expressway and underground logistics system in mega cities-a new idea for solving traffic problems in China's megacities," Science and Technology Review, vol. 4, no. 4, pp. 3-6, 2004.
[9] Z. Chen, J. Dong, and R. Ren, "Urban underground logistics system in China: opportunities or challenges?," Underground Space, vol. 2, no. 3, 2017.

[10] M. C. van der Heijden, A. V. Harten, M. J. R. Ebben, Y. A. Saanen, E. C. Valentin, and A. Verbraeck, "Using simulation to design all automated underground system for transporting freight around Schiphol airport," Interfaces, vol. 32, no. 4, pp. 1-19, 2002.

[11] V. Johan, "Underground logistics systems for goods distribution in urban areas: overview and experience in the Netherlands," in Proccedings of the ISUFT 2005, Shanghai, China, 2005.

[12] J. Zhu, K. Huang, Y. Pu, and J. Zhang, "Research on optimization model for urban underground logistics system," in Proccedings of the International Conference on Transportation Engineering, pp. 4192-4197, Chengdu, China, July 2007.

[13] B. Erkayman, E. Gundogar, G. Akkaya, and M. Ipek, "A fuzzy TOPSIS approach for logistics center location problem," Journal of Business Case Studies (JBCS), vol. 7, no. 3, pp. 49-54, 2011.

[14] Z. Turskis and E. K. Zavadskas, "A new fuzzy additive ratio assessment method (ARAS-F). Case study: the analysis of fuzzy multiple criteria in order to select the logistic centers location," Transport, vol. 25, no. 4, pp. 423-432, 2010.

[15] Q. Guo and J. Zhuang, "Measuring the integration level of logistics facilities in Beijing-Tianjin-Hebei based on cloud model," China Business and Market, vol. 32, no. 1, pp. 113121, 2018.

[16] W. T. Yan and Y. H. Qin, "Research on bi-level programming model and algorithm of underground logistics node location," Chinese Journal of Underground Space and Engineering, vol. 12, no. 4, pp. 870-874, 2016.

[17] Q. Q. Li, Optimization Layout of Underground Logistics Network in Big Cities with Plant Growth Simulation Algorithm, Hangzhou Dianzi University, Hangzhou, China, 2013.

[18] V. A. J. Binsbergen and V. Johan, Innovation Steps towards Efficient Goods Distribution Systems for Urban Areas, Delft University of Technology, Delft, The Netherlands, 2001.

[19] S. L. Mu, The Research of Route Planning of Urban Underground Logistics System Based on Beijing, Shijiazhuang TieDao University, Shaoxing, China, 2015.

[20] B. Liu, Uncertainty Theory, Springer-Verlag, Berlin, Germany, 2nd edition, 2007.

[21] B. Liu, Uncertainty Theory: A Branch of Mathematics for Modeling Human Uncertainty, Springer-Verlag, Berlin, Germany, 2010.

[22] X. Gao and Y. Gao, "Connectedness index of uncertain graph," International Journal of Uncertainty, Fuzziness and Knowledge-Based Systems, vol. 21, no. 1, pp. 127-137, 2013.

[23] Y. Gao, "Uncertain models for single facility location problems on networks," Applied Mathematical Modelling, vol. 36, no. 6, pp. 2592-2599, 2012.

[24] C. K. Ting, S. T. Li, and C. N. Lee, "TGA: a new integrated approach to evolutionary algorithms," IEEE Congress on Evolutionary Computation, vol. 2, no. 2, pp. 917-924, 2001.

[25] Y. Gao, "Analysis of k-out-of-n system with uncertain lifetimes," in Proceedings of the Eighth International Conference on Information and Management Sciences, pp. 794-797, Kunming, China, September 2009.

[26] B. Xiao-ping, Z. Yu-hong, and L. Ya-nan, “A novel approach to study real-time dynamic optimization analysis and simulation of complex mine logistics transportation hybrid system with belt and surge links," Discrete Dynamics in Nature and Society, vol. 2015, Article ID 601578, 8 pages, 2015. 
[27] L. Y. Zhang, T. Fei, and Y. S. Sun, "The Research about simulated annealing ant colony algorithm in emergency logistics path optimization," Advanced Materials Research, vol. 482-484, pp. 2470-2474, 2012.

[28] Z. C. Hua, H. Xin, and Z. Wei, "Logistics distribution routing optimization algorithm," Applied Mechanics and Materials, vol. 513-517, pp. 1740-1743, 2014. 


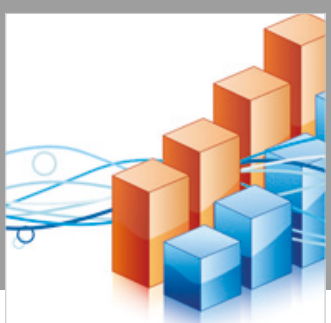

Advances in

Operations Research

\section{-n-m}
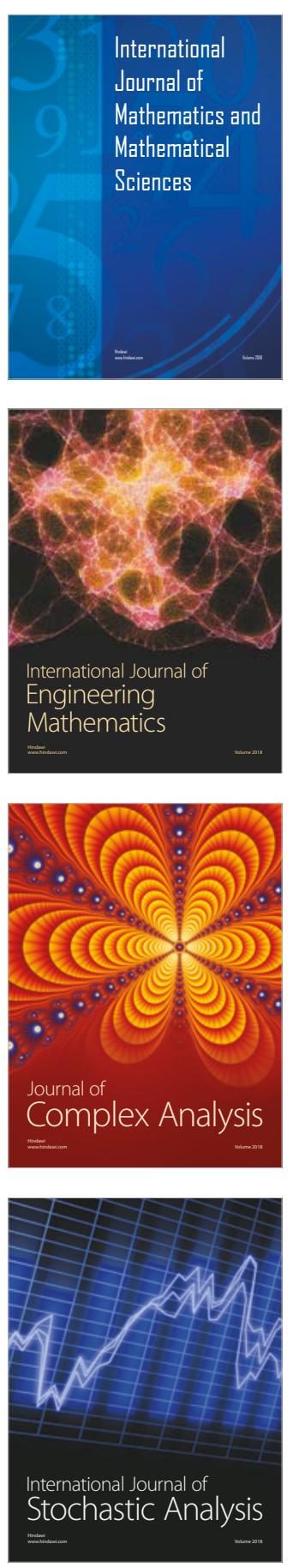
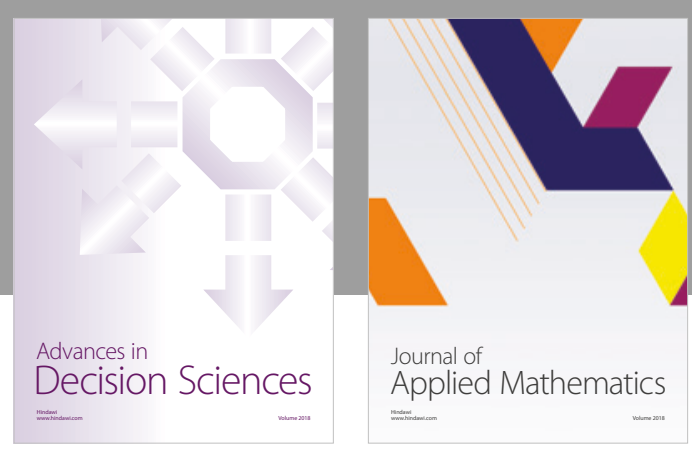

Journal of

Applied Mathematics
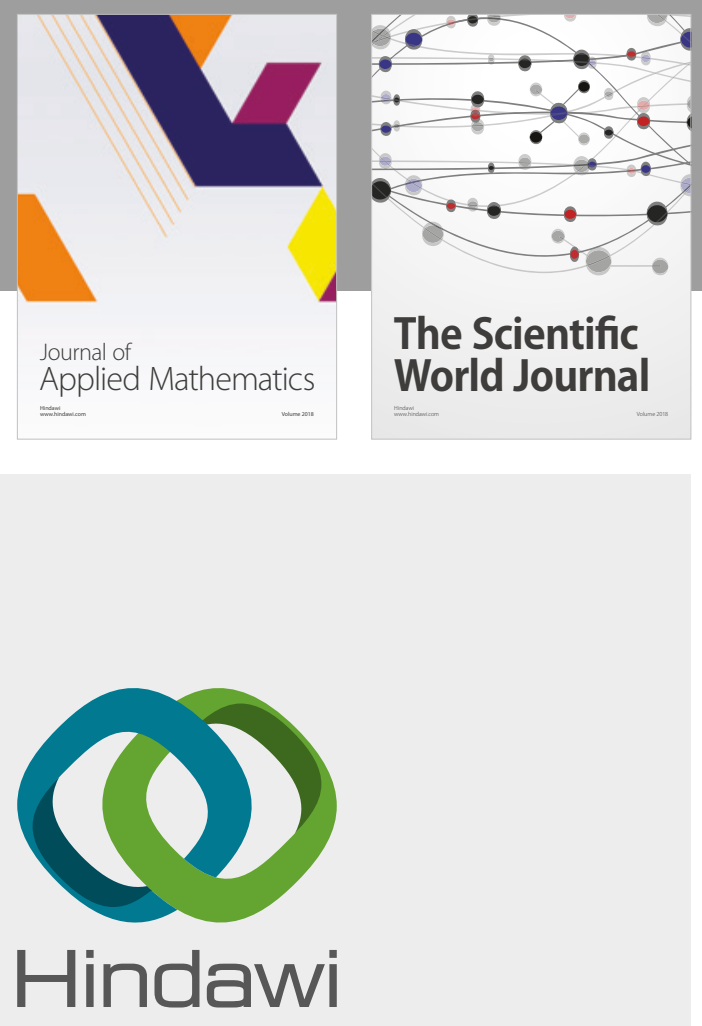

Submit your manuscripts at

www.hindawi.com

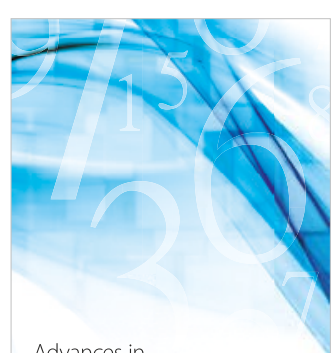

Advances in
Numerical Analysis
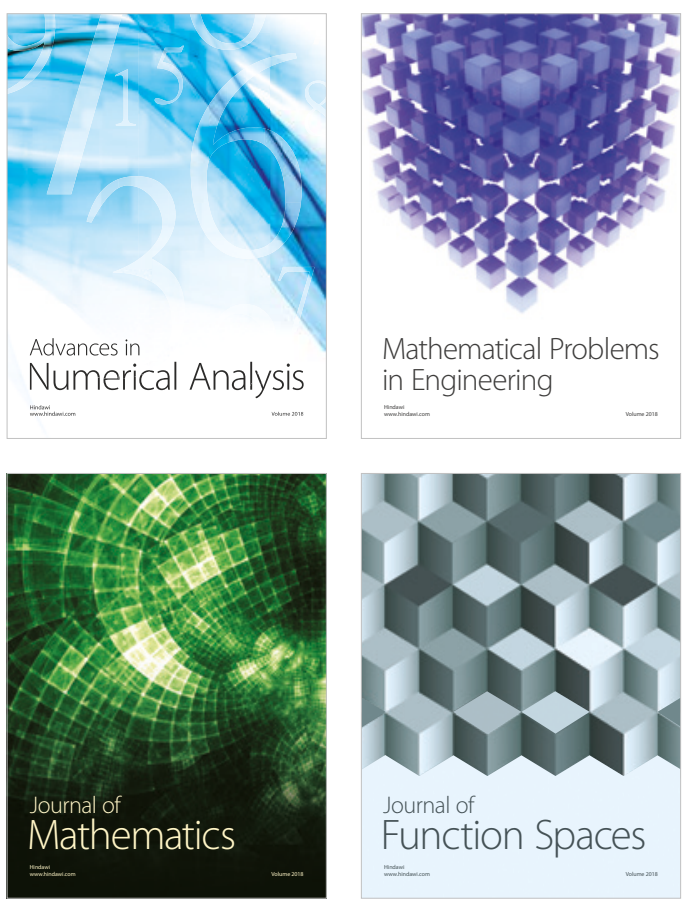

Mathematical Problems in Engineering

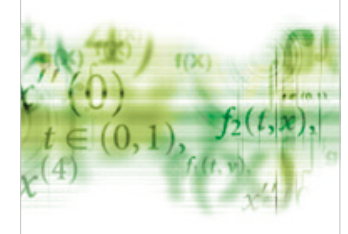

International Journal of

Differential Equations

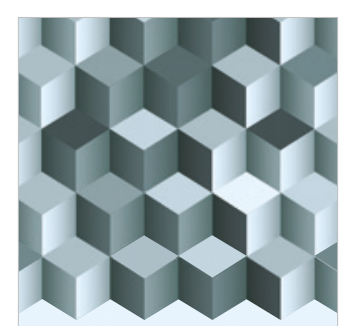

Journal of

Function Spaces

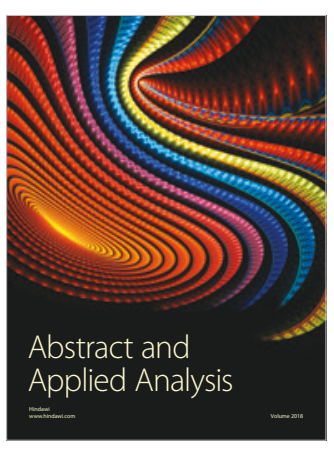

The Scientific

World Journal

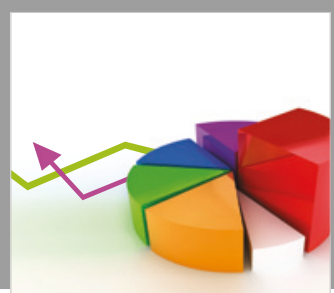

Journal of

Probability and Statistics
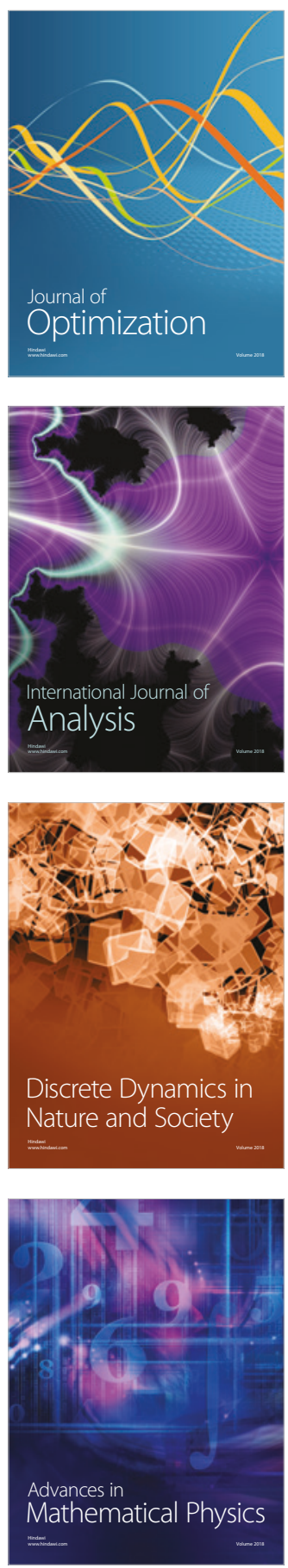